\title{
Penyampaian Profile Dinas Komunikasi dan Informatika dengan Media Video di Kota Tangerang Selatan
}

\author{
Dewi Immaniar Desrianti* ${ }^{1}$, Arsi Yulianjani ${ }^{2}$, Adellia Sylviani ${ }^{3}$ \\ ${ }^{123}$ Program Studi Teknik Informatika, Fakultas Sains and Teknologi, Universitas Raharja \\ Email: dewi.immaniar@ raharja.info ${ }^{* 1}, \underline{\text { arsiyulianjani@ }^{2} \text { raharja.info }}{ }^{2}, \underline{\text { adellia @ raharja.info }^{3}}$
}

\begin{abstract}
Abstrak
Media audio dan visual dalam perkembangan zaman saat ini cukup banyak dimanfaatkan sebuah instansi atau perusahaan sebagai media promosi dan pengenalan profile mereka. Video Profile menjadi salah satu media promosi tersebut. Kota Tangerang Selatan merupakan salah satu Kota di Provinsi Banten dan Humas Kota Tangerang Selatan yang dikelola oleh Dinas Komunikasi dan Informatika (DISKOMINFO), bertugas dalam memberikan informasi tentang perkembangan Kota Tangerang Selatan kepada masyarakat. Maka dari itu, permasalahan yang dihadapi saat ini adalah membuat video profil Kota Tangerang Selatan yang terbaru untuk update data dan informasi sampai tahun 2019 dari video profile lama pada tahun 2014. Tujuan dari penelitian ini adalah untuk membantu Humas Kota Tangsel dalam memberikan dan menyebarkan informasi yang terbaru kepada masyarakat tentang perkembangan Kota Tangerang Selatan selama 5 tahun terakhir. Manfaat penelitian ini dapat memudahkan Humas Kota Tangsel untuk memberikan informasi kepada masyarakat dalam bentuk audio visual. Penelitian ini menggunakan metode penelitian pengumpulan data, analisa perancangan media dan konsep produksi media (KPM) yaitu : preproduction, production, dan postproduction. Hasil penelitiannya berupa peningkatan dari media video profile Kota Tangerang Selatan pada Diskominfo Kota Tangerang Selatan. Melalui peningkatan dari video profile ini, diharapkan dapat membantu sie Humas kota Tangsel untuk menyebarkan serta memberikan informasi yang update, kreatif, atraktif dan informatif tentang Kota Tangerang Selatan sesuai yang diinginkan.
\end{abstract}

Kata Kunci - Video, Profile, Media, Informasi, Tangerang Selatan

\begin{abstract}
Audio and visual media in today's times are quite widely used by an agency or company as a media for promotion and introduction to their profile. Video Profile is one of the promotional media. South Tangerang City is one of the cities in Banten Province and the Public Relations of South Tangerang City which is managed by the Communication and Informatics Office (DISKOMINFO), which is tasked with providing information about the development of South Tangerang City to the public. Therefore, the problem currently faced is making the latest South Tangerang City video profile to update data and information until 2019 from an old video profile in 2014. The purpose of this research is to assist the Public Relations of Tangsel City in providing and disseminating the latest information to the public about the development of South Tangerang City during the last 5 years. The benefits of this research can make it easier for the Public Relations of Tangsel City to provide information to the public in audio-visual form. This research uses research methods of data collection, analysis of media design and the concept of media production (KPM), namely: preproduction, production, and postproduction. The results of his research were in the form of an increase in the media video profile of South Tangerang City at Diskominfo of South Tangerang City. Through the enhancement of this video profile, it is hoped that it can help the PR department of Tangsel to disseminate and provide updated, creative, attractive and informative information about South Tangerang City as desired.
\end{abstract}

Keyword - Video, Profile, Media, Information, South Tangerang

165

Vol. 1 No. 2 -Agustus 2020 


\section{PENDAHULUAN}

Media audio dan visual dalam perkembangan zaman saat ini cukup banyak dimanfaatkan sebuah instansi atau perusahaan sebagai media promosi dan pengenalan profile mereka. mengenai visi, misi, produk, jasa dan prestasi apa saja yang mereka miliki. Audio visual yakni perangkat sound system yang dilengkapi dengan penampilan gambar, biasanya digunakan untuk presentasi, home theater dan sebagainya ${ }^{[1]}$. Bentuk penyampaian informasi tersebut yaitu video profile.

Video profile atau Company Profile yaitu sebuah gambaran mengenai instansi perusahaan atau riwayat seseorang mencapai kesuksesan, dalam hal hasil karya yang telah dihasilkan serta diterima di kalangan masyarakat luas ${ }^{[2]}$.

Kota Tangerang Selatan adalah Kota yang berada di Provinsi Banten, dengan luas wilayah 164,86 km² yang terdiri dari 7 Kecamatan dan 54 Kelurahan, Kota Tangerang Selatan memiliki jumlah penduduk sebanyak 1.696.308 jiwa pada tahun 2019 dan menjadi salah satu daerah tujuan urbanisasi untuk masyarakat.

Humas Kota Tangerang Selatan terletak di Gedung 1 Lt. 6 Pusat Pemerintahan Kota Tangerang Selatan, yang beralamatkan di Jl. Maruga Raya No. 1 Kec. Ciputat, Kota Tangerang Selatan, dikelola oleh Dinas Komunikasi dan Informatika (DISKOMINFO), selalu aktif menyebarkan berita tentang Kota Tangerang Selatan, serta tugas dari Diskominfo Kota Tangsel seperti, membuat video iklan layanan masyarakat, video profile instansi pemerintah, desain grafis untuk ucapan hari besar dan video promosi.

Permasalahan dalam penelitian ini yaitu Pemerintah Kota Tangerang Selatan sebelumnya sudah memiliki video profile yang dibuat pada tahun 2014 tetapi belum diperbarui sesuai dengan data atau informasi terbaru sampai tahun 2019, oleh karena itu dirasakan sudah tidak update lagi dan sudah tidak efektif dalam memberikan informasi-informasi terbaru kepada masyarakat luas.

Tujuan Penelitian ini yaitu untuk membantu Humas Diskominfo Tangerang Selatan dalam memberikan informasi terbaru kepada masyarakat tentang perkembangan Kota Tangerang Selatan selama 5 tahun terakhir, yang sebelumnya video profile Kota Tangerang Selatan mengambil informasi dan suasana kota yang lama, akan di update dengan informasi tentang gambaran wilayah kota, keuangan daerah, infrastruktur apa saja yang ada dan potensi daerah yang terbaru dan dikemas dengan video yang menarik dan kreatif, sehingga dapat memikat minat investor, wisatawan dan masyarakat untuk bekerjasama dan berkunjung ke Kota Tangerang Selatan.

Untuk itu diperlukan sebuah solusi pemecahan masalah, khususnya untuk menunjang informasi pada Diskominfo Tangerang Selatan, dengan melakukan peningkatan media video profile Kota Tangerang Selatan, sebagai media penunjang presentasi dari pemerintahan Kota Tangerang Selatan, yang diperlihatkan pada saat kunjungan kerja dari daerah lain, dan berbagai kegiatan Humas Diskominfo lainnya. Video Profile Kota Tangerang Selatan ini juga nantinya akan diimplementasikan melalui Youtube channel dan media sosial Instagram Humas Kota Tangsel, sehingga masyarakat dapat dengan mudah memperoleh informasi tentang Kota Tangerang Selatan.

Dengan demikian, dalam penelitian ini bermaksud untuk mengembangkan media video profile Kota Tangerang Selatan pada Dinas Komunikasi dan Informasi Kota Tangerang Selatan, yang diharapkan dapat membantu sie Humas dalam memberikan gambaran yang menarik, kreatif dan informatif tentang Kota Tangerang Selatan sesuai yang diinginkan.

Beberapa penelitian yang berkaitan dengan Peningkatan media video profile ini seperti penelitian yang dilakukan oleh Handayani, dkk (2019) "Video Company Profile Live Kota Tangerang Dengan Teknik Editing Menggunakan Adobe Premiere Pro" Penelitian yang memperkenalkan program pemerintah Kota Tangerang, kemudian di upload dalam You Tube dengan tujuan dapat dilihat oleh masyarakat luas, khususnya warga Kota Tangerang dengan hasil berupa video profile program Kota Tangerang LIVE dibuat dalam format mp4. 
Selanjutnya, penelitian yang dilakukan Kausar, dkk (2015) $)^{[4]}$ "Perancangan Video Company Profile Kota Serang Dengan Teknik Editing Menggunakan Adobe Premiere Pro Cs5".

Penelitian ini bertujuan untuk membuat video company profile pada kota serang sebagai media informasi dan promosi. Dalam membuat video company profile, software yang digunakan yaitu adobe premier Pro CS5 dalam proses editing dan penambahan teks serta animasi dengan hasil dalam format mp4.

Lalu, penelitian yang dilakukan oleh Putra dan Vella Carisa (2019) ${ }^{[5]}$ "Video Kabupaten Tangerang Pada Dinas Disporabudpar Pariwisata" Penelitian ini memiliki tujuan untuk mencapai target Disporabudpar dalam hal menyampaikan informasi tentang objek wisata Kabupaten Tangerang kepada masyarakat dan wisatawan, serta meningkatkan jumlah kunjungan wisatawan setiap tahunnya dengan menggunakan Metode penelitian Pengumpulan Data, Analisa Perancangan Media, dan Konsep Produksi Media (KPM) yang meliputi : pre production, production, dan post production. Selanjutnya, penelitian yang dilakukan oleh Sunarya, dkk (2017) ${ }^{[6]}$ dengan judul "Video Profile Sebagai Sarana Informasi Dan Promosi Studio Satu Pt. Media Televisi Indonesia ( Metro Tv )". Media informasi dan promosi yang digunakan Studio Satu Metro TV menyajikan informasi yang efektif, akurat, dan menarik untuk dilihat dari segi tampilan maupun isi. Tujuan dari penelitian ini agar minat masyarakat pada sebuah informasi akan semakin meningkat. Informasi dan promosi yang akan disampaikan pada Studio Satu Metro TV cukup banyak, meliputi : kegiatan kameraman, pengenalan alat switcher, master control room dan lain-lain. Lalu yang terakhir, penelitian yang dilakukan oleh Hidayat, dkk (2016) ${ }^{[7]}$ "Perancangan Media Video Profile Berbentuk Promosi Dan Informasi Di Smk Yuppentek 4 Ciledug Tangerang". Penelitian ini bertujuan untuk merancang media berbasis audio visual agar dapat menjadi daya tarik yang efektif, terutama dalam penyampaian informasi dan promosi mengenai hal - hal yang berkaitan dengan keseluruhan SMK Yuppentek 4 Ciledug Tangerang dengan metode penelitian Pengumpulan Data, Analisa Perancangan Media, dan Konsep Produksi Media (KPM) yang meliputi : pre production, production, dan post production.

\section{METODE PENELITIAN}

Beberapa metode penelitian yang digunakan untuk Peningkatan Video Profile Kota Tangerang Selatan ini yaitu: (1) Metode Pengumpulan Data, yaitu metode yang digunakan untuk mendapatkan data dengan jalan pengamatan (Observasi), interview ataupun dari kajian pustaka. (2) Analisa Perancangan Media yaitu Software apa saja yang dipakai untuk mengedit video. (3) Konsep Produksi Media (KPM). Perancangan media video program ini melalui beberapa proses perancangan agar mendapat gambaran tentang project yang dibuat, sehingga memudahkan dalam membuat video profile ini. Tahapan yang dilakukan adalah Preproduction, Production dan Post Production

\section{HASIL DAN PEMBAHASAN}

\subsection{Preproduction}

Pre production adalah step atau langkah awal dimulainya suatu karya diantaranya ide, perencanaan, dan persiapan dari Konsep Produksi Media. Terdapat tujuh langkah Pre production dalam Konsep Produksi Media, dimulai dari ide yang dituangkan secara sistematis, lalu kemudian pembuatan sinopsis, narasi, script writing, dan storyboard. Lalu tahapan yang lain yaitu rundown, pemilihan pemain (crew produksi) dan setting alat. Semua tahapan yang ada harus sesuai time schedule yang ditetapkan. Berikut ini alur dari prepoction pada gambar 1 dibawah ini. 


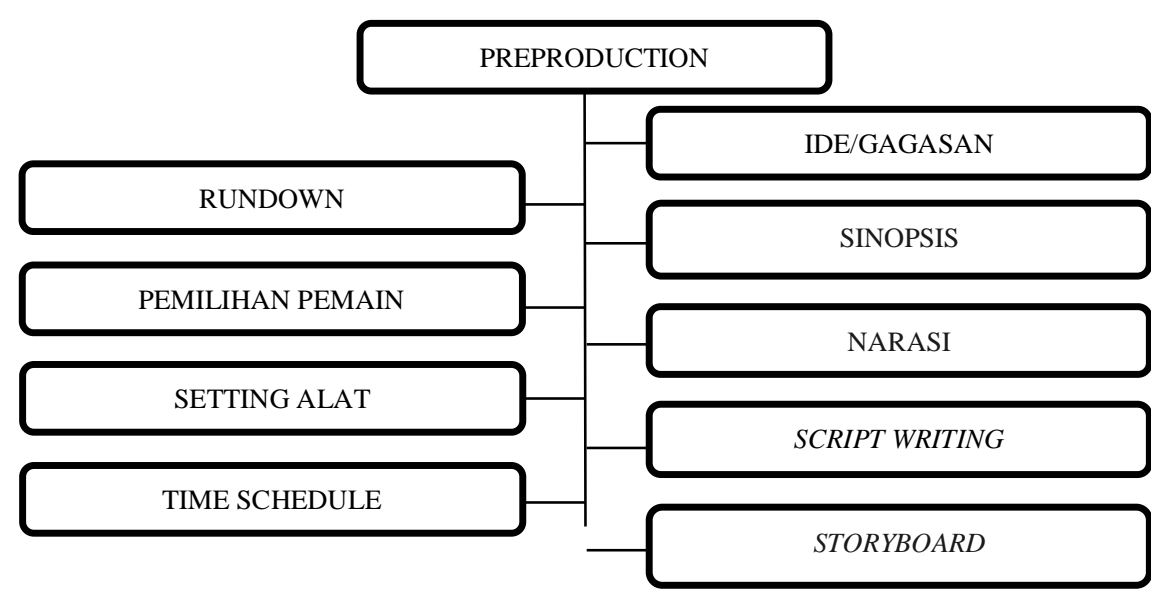

1. Ide/Gagasan

Gambar 1. Preproduction

Ide atau Gagasan adalah sebuah hasil pemikiran atau usulan yang merupakan sebuah rencana awal dari proses pre production, hal itu merupakan hal yang mendasar untuk perancangan sebuah karya video. Sebuah ide atau gagasan yang telah tercipta kemudian dikembangkan lagi dengan mengumpulkan data-data berdasarkan masalah yang ada. Kemudian dalam penelitian ini konsep yang dibutuhkan dalam pengembangan video profile Kota Tangerang Selatan menampilkan informasi tentang Gambaran Wilayah Kota, APBD, Infrastruktur Daerah dan Potensi Daerah yang ada di Kota Tangerang Selatan dengan konsep yang menarik dengan penambahan effect visual dan juga voice over agar dapat meningkatkan minat wisatawan dan juga investor yang ingin berinvestasi.

2. Sinopsis atau Cerita

Sinopsis adalah sebuah ringkasan dari sebuah cerita yang disusun secara sistematis dan dapat membantu pembaca atau penonton untuk melihat ringkasan dari cerita tersebut. Berikut adalah sinopsis dari video profile Kota Tangerang Selatan:

"Di awal video, menampilkan intro bumper berupa dari Humas Kota Tangsel, lalu video dari atas jam Alam Sutera, Hyperlapse dari gedung Walikota Tangsel, video anak sekolah dan ruangan panggilan darurat 112 Kota Tangsel. Selanjutnya menampilkan gedung Teras Kota pada malam hari, tempat ibadah seperti : masjid, gereja, Pura dan Wihara, video suasana dari atas jalan Bintaro. Lalu, menampilkan video pemberian bantuan ke masyarakat dari Wali Kota Tangsel, karyawan sedang bekerja didepan komputer, video suasana masyarakat sedang jogging dan pengrajin rotan yang sedang membuat bangku. Selanjutnya, menampilkan video infografis tata letak Kota Tangsel dari atas, motion grafis luas dan kecamatan Kota Tangsel, video suasana masyarakat di pasar modern BSD, gedung ITC Serpong dan video grafis tulisan jumlah penduduk Kota Tangsel. Selanjutnya, menampilkan video grafis tulisan jumlah bantuan pendidikan yang diberikan Walikota Tangsel sekaligus video gedung dan anak sekolah, video grafis tulisan jumlah anggaran kesehatan Kota tangsel sekaligus video di puskesmas dan masyarakat yang sedang berobat, video grafis tulisan jumlah infrastruktur yang sudah dibuat oleh pemerintah Kota Tangsel, video grafis tulisan APBD Kota Tangsel tahun 2018-2019, menampilkan screen capture dari aplikasi Tangselpay dan ruangan panggilan darurat 112 Kota Tangsel, menampilkan video wisata-wisata di Kota Tangsel lalu logo pemerintah, Humas Kota Tangsel dan Logo Universitas Raharja lalu terakhir menampilkan Credit title". 
3. Narasi

Narasi adalah tulisan yang menyimpan berbagai pikiran, ide dan gagasan yang dikemas dengan konsep yang menarik lalu akan ditampilkan menjadi sebuah naskah akhir lalu akan ditampilkan visualisasinya, sehingga kalimat ini menjadi bahan untuk proses dubbing atau perekaman voice over. Narasi juga dapat memperjelas alur cerita dari video yang disampaikan. Berikut ini adalah naskah dubbing/ voice over pada video profile Kota Tangerang Selatan :

"Kota Tangerang Selatan// kota yang cerdas/ modern/ dan religius// itulah motto yang dijadikan pilar dasar pembangunan/serta pelayanan kepada masyarakat// Sehingga/ dapat mengembangkan sumber daya manusianya menjadi kota yang layak huni/ mengembangkan ekonomi masyarakat/ dan meningkatkan tata kelola pemerintahan yang baik// kota Tangerang Selatan/adalah kota ke-8 di wilayah provinsi Banten/dan memiliki lokasi yang strategis/ karena berbatasan langsung dengan ibu kota DKI Jakarta/ dan kota Tangerang di sebelah utaral/ Di sebelah timur berbatasan dengan DKI Jakarta dan kota Depok/l sebelah selatan/ berbatasan dengan kabupaten Bogor dan kota Depok provinsi jawa barat/ serta sebelah barat berbatasan dengan kabupaten Tangerang// Dengan luas wilayah 164,86 KMㄹ / Kota Tangerang Selatan/terdiri dari 7 kecamatan/dan memiliki 54 kelurahan// antara lain/ kecamatan Serpong/ 28,27 persen/ kecamatan Serpong Utara/ 22,36 persen/ kecamatan Ciputat/21,11 persen/ kecamatan Ciputat Timur/ 17,82 persen/ kecamatan Pamulang/28,74 persen/ kecamatan Pondok Aren/29,80 persen/ dan kecamatan Setu/ 16,76 persen// Dengan luas wilayah sebesar itu/ jumlah penduduk di Kota Tangerang Selatan mencapai sebanyak/ 1.696.308 jiwa/l Menurut data BPS Kota Tangerang Selatan tahun 2019// Sebagai kota yang cerdas/ sampai tahun 2018/ angka rata-rata setiap anak yang menempuh pendidikan formal di Kota Tangerang Selatan mencapai/ 12 tahun atau setara dengan tingkat SMA// Lalu/ jumlah fasilitas pendidikan yang terdiri dari/ TK/ SD/ SMP/ SMA ATAU SMK/ dan Universitas/ berjumlah/ 1008 gedung/ yang tersebar di Kota Tangerang Selatan// Pada bidang kesehatan/total anggaran kesehatan Kota Tangerang Selatan sebesar/ 449 miliar rupiah// Bersumber dari APBD Kabupaten atau Kotal APBD Provinsi/ dan APBN// Di bidang infrastruktur/ telah membangun dan melebarkan jalan sepanjang/ 405,664 kilometer// Lalu/ jumlah fasilitas peribadatan di Kota Tangerang Selatan berjumlah/ 1.912 gedung// Terdiri dari masjid/ mushola/ gereja/ vihara/ pura/ dan kelenteng// Dengan itu/ ini dia jumlah Pendapatan Belanja Daerah Kota Tangerang Selatan// Dengan moto menjadi kota modern/pemerintah Kota Tangerang Selatan/ telah membuat produk produk layanan publik seperti/ Aplikasi TANGSELPAY/ dan layanan panggilan darurat 112/ agar masyarakat lebih aman dan sejahtera kedepannyall Potensi wisata yang dimiliki juga tidak kalah menariknya/l Pusat perbelanjaan di Kota Tangerang Selatan/ menjadi wisata menarik bagi warga sekitar maupun warga daerah lain yang ingin berkunjung// Taman taman yang asri dan unik/ juga menjadi daya tarik lain bagi masyarakat yang ingin berwisata di Kota Tangerang Selatan//".

\section{Pembuatan Storyboard}

Storyboard merupakan sebuah sketsa gambar yang menjelaskan tentang bagian-bagian yang ada di dalam ide cerita, agar lebih mempermudah dalam memahami dan implementasi cerita tersebut. Berikut ini Storyboard yang digambarkan per-scene, berdasarkan alur cerita yang dirancang pada video profile Kota Tangerang Selatan. Pada gambar 2, scene 1, Menampilkan video bumper opening dari Humas Kota Tangsel, pada gambar 3, scene 2, Menampilkan video dari atas jam Alam Sutera dengan angle kamera Bird Eye diambil pada siang hari. Lalu gambar 4, scene 3, Menampilkan video hyperlapse gedung Walikota Tangerang Selatan dengan angle kamera wide shot diambil pada waktu di siang hari. Pada gambar 5, scene 4, Menampilkan video anak sekolah sedang menari dengan angle kamera 
medium shot diambil pada siang hari. Lalu, di gambar 7, scene 5, Menampilkan video motion grafis luas dan kecamatan Kota Tangsel dan yang terakhir gambar 8, scene 6, Menampilkan video tulisan I love Tangsel dengan angle kamera medium long shot diambil pada siang hari.

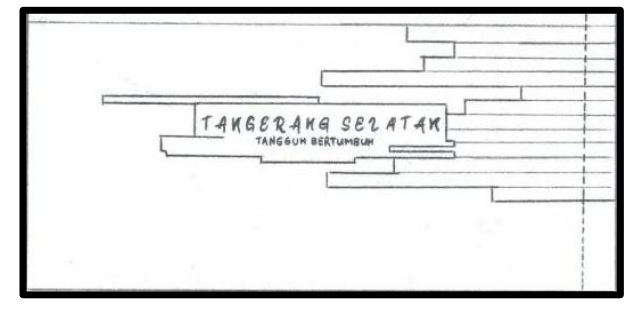

Gambar 2. Scene 1/ Menampilkan video bumper opening dari Humas Kota Tangsel

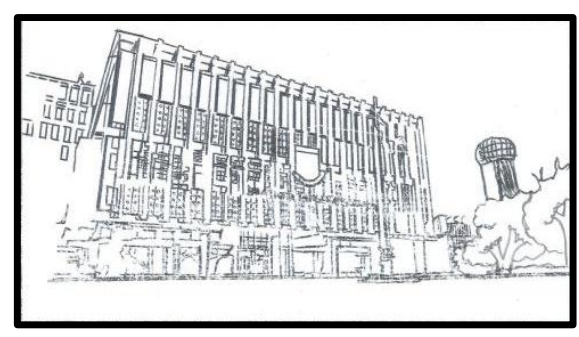

Gambar 4. EXT/ Scene 3/Day/ Wide Shot/ Menampilkan video hyperlapse gedung Walikota Tangerang Selatan

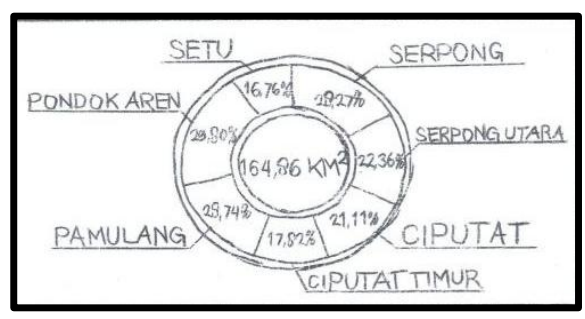

Gambar 6. Scene 5/ Menampilkan video motion grafis luas dan kecamatan Kota Tangsel

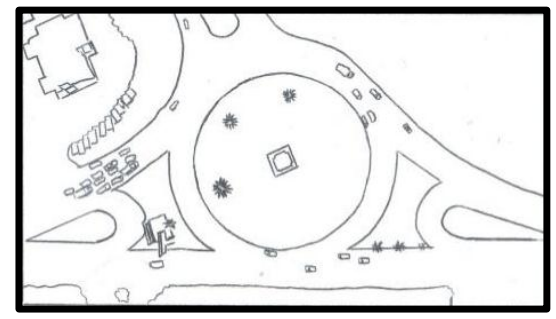

Gambar 3. EXT/ Scene 2/ / Day/ Bird Eyel

Menampilkan video dari atas jam Alam Sutera

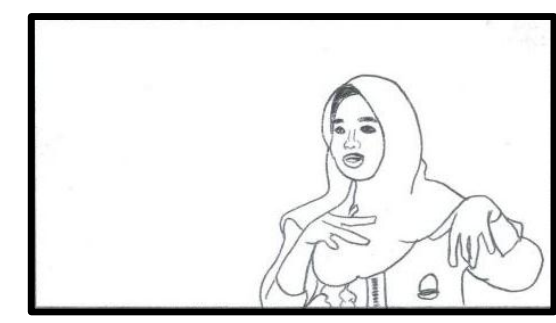

Gambar 5. EXT / Scene 4 / Day / Medium shot / Menampilkan video anak sekolah sedang menari

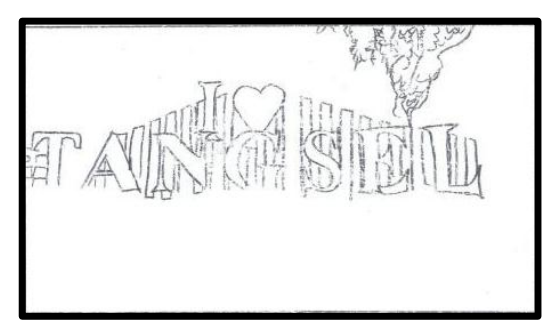

Gambar 7. EXT/ Scene 6/ Day/ Medium Long Shot/ Menampilkan video tulisan I love Tangsel

\section{Script Writing}

Script writing dalam video profile Kota Tangerang Selatan ini adalah gambaran alur cerita dari video tersebut yang terdiri dari visual dan audio dari naskah untuk voice over, yang ada pada tabel 1 dibawah ini. 
Tabel 1. Script Writing

\begin{tabular}{|c|c|c|}
\hline No. & VISUAL & AUDIO \\
\hline 1 & $\begin{array}{l}\text { Menampilkan bumper Humas } \\
\text { Tangsel }\end{array}$ & Music. \\
\hline 2 & Menampilkan video jam Alam Sutera & Music. \\
\hline 3 & $\begin{array}{l}\text { Menampilkan video hyperlapse } \\
\text { gedung waliKota Tangerang Selatan }\end{array}$ & Kota Tangerang Selatan// \\
\hline 4 & Menampilkan video anak sekolah & kota yang cerdas/ \\
\hline 5 & $\begin{array}{l}\text { Menampilkan video motion grafis } \\
\text { luas dan kecamatan Kota Tangsel }\end{array}$ & $\begin{array}{l}\text { Dengan luas wilayah } 164,86 \mathrm{KM}^{2} \text { / } \\
\text { Kota Tangerang Selatan/ terdiri dari } 7 \\
\text { kecamatan/ dan memiliki } 54 \\
\text { kelurahan// antara lain/ kecamatan } \\
\text { Serpong/ } 28,27 \text { persen/ kecamatan } \\
\text { Serpong Utara/ } 22,36 \text { persen/ } \\
\text { kecamatan Ciputat/ } 21,11 \text { persen/ } \\
\text { kecamatan Ciputat Timur/ } 17,82 \\
\text { persen/ kecamatan Pamulang/ } 28,74 \\
\text { persen/ kecamatan Pondok Aren/ } \\
29,80 \text { persen/ dan kecamatan Setu/ } \\
\text { 16,76 persen// }\end{array}$ \\
\hline 6 & Menampilkan video I love tangsel & Music. \\
\hline
\end{tabular}

6. Rundown

Rundown merupakan jadwal atau urutan isi kegiatan seperti perencanaan gambar, suara, lokasi pengambilan gambar dan durasi waktu saat melakukan shooting atau sebuah acara. Berikut rundown dari video profile Kota Tangerang Selatan pada tabel 2 berikut ini :

Tabel 2. Rundown

\begin{tabular}{|c|c|c|c|c|c|}
\hline No. & Scene & Location & Duration & INT/EXT & Description \\
\hline 1 & 2 & $\begin{array}{l}\text { video jam Alam } \\
\text { Sutera }\end{array}$ & $00: 25-00: 28$ & $E X T$ & $\begin{array}{l}\text { Menampilkan video } \\
\text { dari atas jam di Alam } \\
\text { Sutera }\end{array}$ \\
\hline 2 & 3 & $\begin{array}{l}\text { Gedung } \\
\text { Walikota } \\
\text { Tangerang } \\
\text { Selatan }\end{array}$ & $00: 28-00: 30$ & $E X T$ & $\begin{array}{lr}\text { Menampilkan } & \text { video } \\
\text { hyperlapse } & \text { gedung } \\
\text { Walikota } & \text { Tangerang } \\
\text { Selatan } & \end{array}$ \\
\hline 3 & 4 & $\begin{array}{l}\text { SMA Negeri } 3 \\
\text { Kota Tangsel }\end{array}$ & $00: 30-00: 32$ & EXT & $\begin{array}{l}\text { Menampilkan video } \\
\text { anak sekolah sedang } \\
\text { membaca buku di } \\
\text { halaman sekolah }\end{array}$ \\
\hline 4 & 6 & $\begin{array}{l}\text { Jaletreng } \\
\text { Riverpark }\end{array}$ & 03:30-03:32 & $E X T$ & $\begin{array}{l}\text { Menampilkan tulisan I } \\
\text { Love Tangsel yang } \\
\text { berada di Jaletreng } \\
\text { Riverpark }\end{array}$ \\
\hline
\end{tabular}


Dalam Penyusunan crew, dibutuhkan ketentuan dalam memberikan jobdesk pada crew, pada sebuah pembuatan video di dalam penyusunan crew terdapat Sutradara, Camera Person, Assistant Cameraman, Lightingman, Audioman, Script Writer, Editor, Dubber dan Talent. Berikut adalah susunan pemain dan crew yang terlibat pada peningkatan video profile Kota Tangerang Selatan pada tabel 3 di bawah ini.

Tabel 3. Susunan Crew

\begin{tabular}{|c|c|c|}
\hline NO. & JABATAN & NAMA \\
\hline 1 & Sutradara & Adellia Sylviani \\
\hline 2 & Camera Person & Adellia Sylviani \\
\hline 3 & Assistant Cameraman & Rizky Ramadhan \\
\hline 4 & Audioman & Adellia Sylviani \\
\hline 5 & Lightingman & Yoga Aji Pratama \\
\hline 6 & Editor & Adellia Sylviani \\
\hline 7 & Script Writer & Adellia Sylviani \\
\hline 10 & Dubber & Leovina Putri \\
\hline 11 & Talent & Ridha Maharani dan \\
& & Wulan \\
\hline
\end{tabular}

8. Analisa Perancangan Media

Dalam peningkatan video profile Kota Tangerang Selatan ini menggunakan software komputer grafis yaitu : Adobe Premiere Pro CC, Adobe After Effect Pro CC dan Adobe Audition CS6.

\section{Time schedule}

Time Schedule merupakan jadwal waktu yang diperkirakan untuk menyelesaikan proses produksi secara keseluruhan dengan waktu yang ditetapkan. Berikut adalah time schedule perancangan video profile Kota Tangerang Selatan pada tabel 3 di bawah ini. 
Tabel 4. Time Schedule

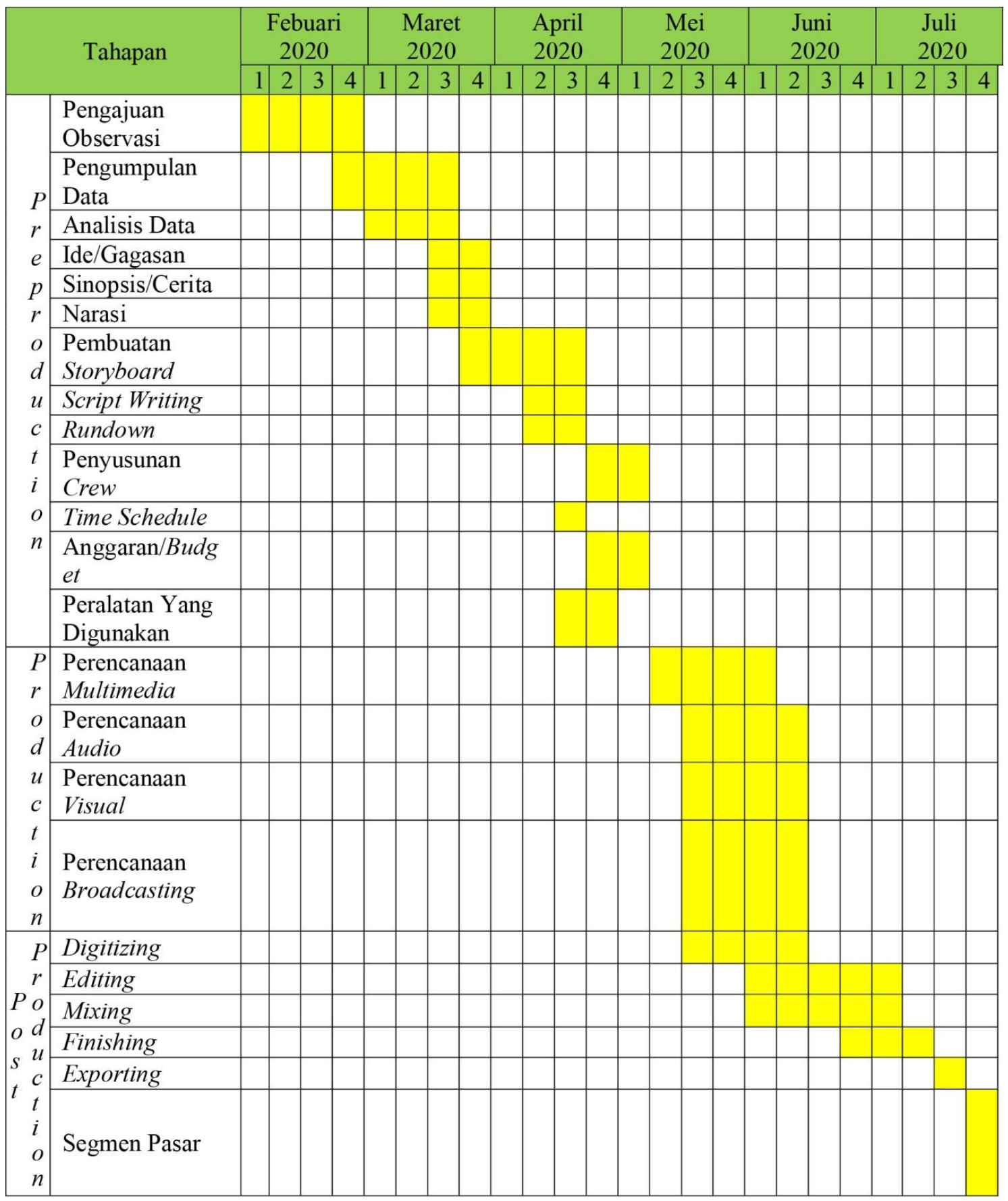

\subsection{Production}

Production adalah tahap selanjutnya dalam konsep produksi media. Dalam proses produksi, kerjasama antara talent dan crew sangat dibutuhkan. Bahkan setiap crew dari masing - masing job desk harus menjalin kerjasama yang solid. Dalam pengembangan Video Profile Kota Tangerang Selatan, ide atau gagasan yang telah dibuat sebelumnya dimasukkan kedalam proses shooting dan perlu persiapan pada tahap produksi yang harus diperhatikan dengan baik seperti semua unsur teknis, naskah, pemain, dan sinematografi yang dijalankan sesuai dengan arahan Sutradara. Dalam tahap production, berikut adalah 
gambaran yang harus dipersiapkan dengan baik seperti perencanaan multimedia, perencanaan visual, perencanaan audio, perencanaan broadcasting. Perancangan multimedia adalah penggabungan bentuk kombinasi dari tiga elemen yaitu gambar / ilustrasi, teks, dan suara dengan tujuan menciptakan video yang dinamis serta interaktif. Dalam video profile, menyampaikan informasi penting dan membutuhkan perencanaan audio agar video menjadi informatif, kreatif dan komunikatif yang disampaikan ke audiens. Perencanaan visual adalah proses persiapan dari beberapa unsur visual seperti gambar, teks, infografis dan visual effect yang akan ditampilkan dalam sebuah video yang utuh. Perencanaan Broadcasting adalah tahapan akhir dari proses production. Dalam perencanaan broadcasting dibutuhkan promosi menarik dan kreatif yang memiliki tujuan untuk menjangkau sasaran yang lebih luas dengan penyebaran yang efektif serta efisien sehingga perencanaan broadcasting sangat perlu dilakukan.

\subsection{Post Production}

Post Production adalah proses finishing atau proses akhir dari sebuah karya sampai menjadi sebuah video yang utuh dan mampu menyampaikan isi atau pesan kepada audience. Dalam proses post production semua gambar yang didapat pada proses production dikumpulkan di edit oleh seorang editor. Kegiatan pemasaran dan distribusi juga masuk di dalam proses post production. Tahapan post production selanjutnya ialah proses digitizing, editing, mixing, finishing, exporting dan segmen pasar. Tahapan Digitizing adalah tahapan proses perapihan dan pemindahan data dari kamera hasil shooting kedalam laptop, agar lebih mudah untuk memilih pengambilan gambar dan angle yang terbaik untuk nanti digunakan saat editing. Lalu, Tahapan editing ini dilakukan setelah tahapan digitizing dengan menyusun video dan memotong video sesuai dengan yang diinginkan untuk menghasilkan video yang utuh dan juga memerlukan waktu yang cukup lama agar hasil lebih maksimal. kemudian, tahap selanjutnya itu Mixing yang merupakan tahap menggabungkan beberapa unsur audio visual seperti gambar, visual effect, backsound dan voive over sehingga tercipta video yang menarik. Lalu, Pada tahap finishing, diperlukan untuk mengecek ulang agar tidak ada file video yang hilang atau rusak dan juga memastikan semua gambar, backsound, voice over, visual effect dan lowthird tersusun rapih dan sesuai dengan susunan Pre Production (Storyboard, Sinopsis, Narasi dan Script Writing). Pada tahapan exporting adalah tahap terakhir dalam proses pembuatan suatu video. Pada tahap segmen pasar ini merupakan tahapan target pasar yang akan dituju untuk menjangkau pangsa pasar. Untuk lebih jelasnya, berikut alur dari post production pada gambar 10 . 


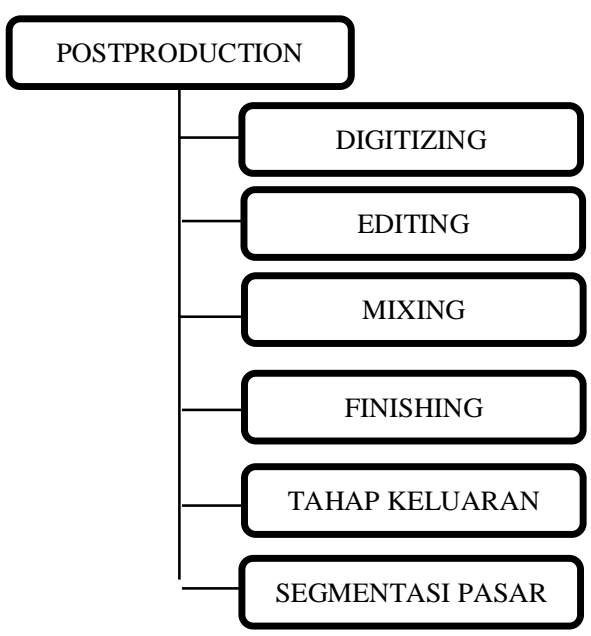

Gambar 8. Post Production

1. Tampilan Isi

Tampilan isi video profile ini dirancang pada saat pembuatan sinopsis. Berikut merupakan tampilan isi video profile yang telah dibuat pada saat proses perancangan Konsep Produksi Media (KPM).

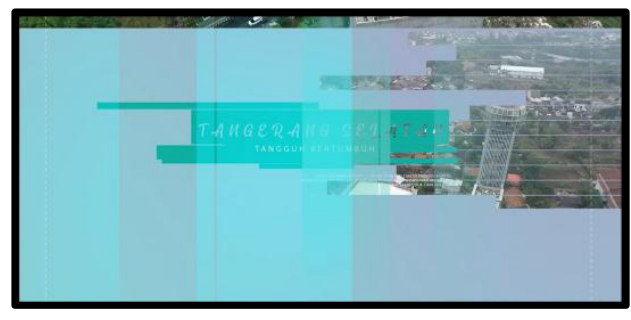

Gambar 9. Scene 1/ Menampilkan video bumper opening dari Humas Kota Tangsel

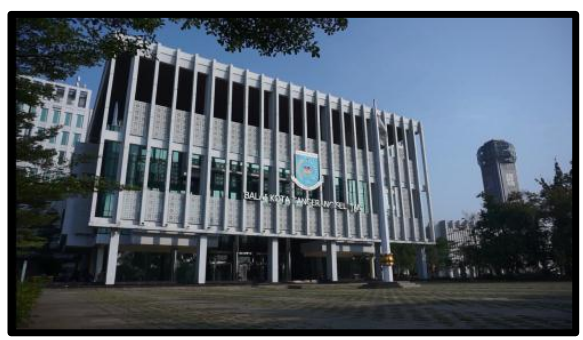

Gambar 11. EXT/ Scene 3/ Day/ Wide Shot/ Menampilkan video hyperlapse gedung wali Kota Tangerang Selatan

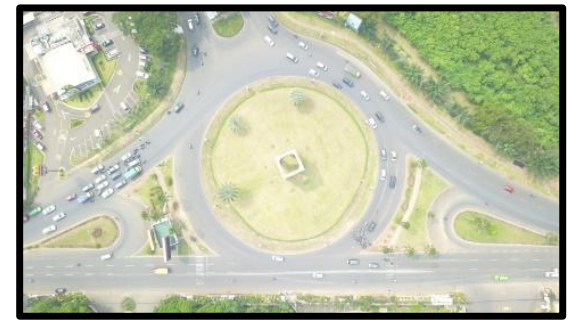

Gambar 10. EXT/ Scene 2/ Day/ Bird Eye/ Menampilkan video dari atas jam Alam Sutera

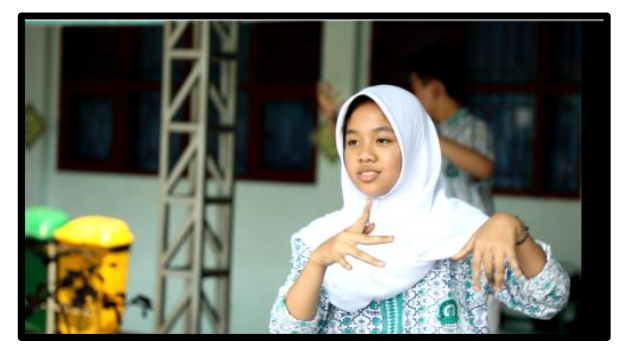

Gambar 12. EXT/ Scene 4/ Day/ Medium shot/

Menampilkan video anak sekolah sedang menari 


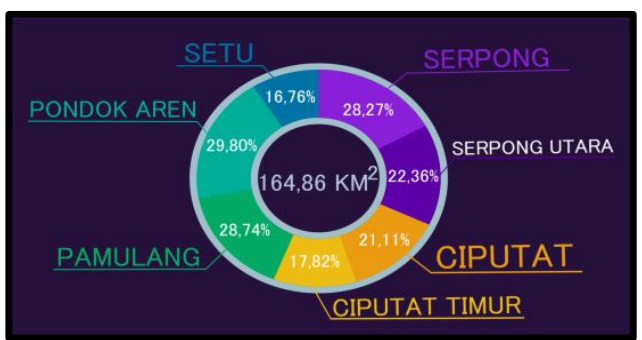

Gambar 13. Scene 5/ Menampilkan video motion grafis luas dan kecamatan Kota Tangsel

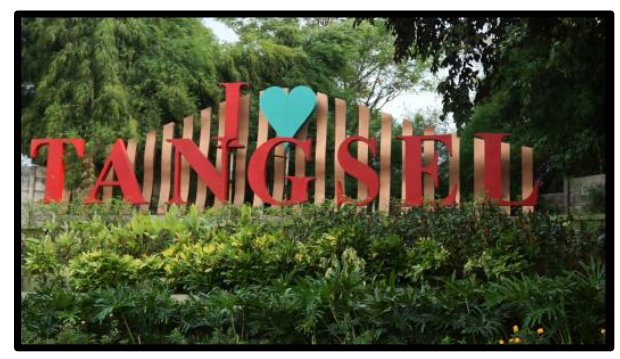

Gambar 14. EXT/ Scene 6/ Menampilkan video tulisan I love Tangsel/ Day/ Medium Long Shot

\section{KESIMPULAN}

Kesimpulan dari Video Profile Kota Tangerang Selatan ini yaitu memberikan informasi kepada masyarakat tentang Kota Tangerang Selatan yang terbaru serta memperbarui video profile yang lama pada tahun 2014 dengan data dan informasi yang update sampai tahun 2019. Lalu, dalam membuat konsep media video profile yang menarik dan dapat memenuhi kebutuhan informasi dan promosi Kota Tangerang Selatan yaitu dengan konsep video yang kreatif dan informatif yang terdapat audio menggunakan musik dan voice over, tampilan visual berkualitas $H D$ dan dilengkapi dengan berbagai visual effect, sehingga dapat menjadi daya tarik bagi masyarakat yang melihatnya, wisatawan maupun investor yang ingin berinvestasi di Kota Tangerang Selatan.

\section{SARAN}

Disarankan kepada Diskominfo Kota Tangerang Selatan untuk dapat lebih mengimplementasikan video profile ini melalui berbagai event yang diadakan oleh Pemerintah Kota Tangerang Selatan dan diinformasikan melalui media sosial seperti Instagram Humas Kota Tangsel, sehingga masyarakat dapat dengan mudah memperoleh informasi tentang perkembangan Kota Tangerang Selatan.

\section{DAFTAR PUSTAKA}

[1] Subekti, T. (2015). Penggunaan Media Audio Elektronika Wireless Microphone Untuk Meningkatkan Partisipasi Siswa SD Pada Pembelajaran Bahasa Indonesia. Jurnal Transformasi, 11(2).

[2] Widada, S., Tama, W., Kusuma, A., \& Lestari, N. Video Profile Sebagai Media Promosi Pada Mts Al-husna Ypihn Curug Kabupaten Tangerang. Journal Cerita, 6(1), 39-51.

[3] Handayani, I., Setiadi, A., \& Ramadani, R. (2019). Video Company Profile LIVE Kota Tangerang Dengan Teknik Editing Menggunakan Adobe Premier Pro. Technomedia Journal, 3(2), 133-145.

[4] Kausar, A., Sutiawan, Y. F., \& Rosalina, V. (2015). Perancangan Video Company Profile Kota Serang Dengan Teknik Editing Menggunakan Adobe Premier Pro CS 5. PROSISKO: Jurnal Pengembangan Riset dan Observasi Sistem Komputer, 2(1). 
[5] Putra, A. A., \& Carisa, V. Video Kabupaten Tangerang pada Dinas Disporabudpar Pariwisata. Cyberpreneurship Innovative and Creative Exact and Social Science, 5(1), 64-73.

[6] Sunarya, L., Nurasiah, D., \& Agustian, F. Video Profile Sebagai Sarana Informasi Dan Promosi Studio Satu PT. Media Televisi Indonesia (Metro TV). Journal Cerita, 3(1), $1-17$.

[7] Hidayat, W., Suhendra, S., \& Maulana, A. Perancangan Media Video Profile Berbentuk Promosi Dan Informasi Di SMK Yuppentek 4 Ciledug Tangerang. Cyberpreneurship Innovative and Creative Exact and Social Science, 2(1), 1-11. 